\title{
Determinants of Radiation Dose in Selective Ophthalmic Artery Chemosurgery for Retinoblastoma
}

\author{
(D)A.M. Qureshi, DL.K. Davies, DP.A. Patel, (D)A. Rennie, and (D) F. Robertson
}

\begin{abstract}
BACKGROUND AND PURPOSE: Retinoblastoma is the most common pediatric ocular neoplasm. Multimodality treatment approaches are commonplace, and selective ophthalmic artery chemosurgery has emerged as a safe and effective treatment in selected patients. Minimizing radiation dose in this highly radiosensitive patient cohort is critical. We explore which procedural factors affect the radiation dose in a single-center cohort of children managed in the UK National Retinoblastoma Service.
\end{abstract}

MATERIALS AND METHODS: A retrospective review was performed of 177 selective ophthalmic artery chemosurgery procedures in 48 patients with retinoblastoma (2013-2017). Medical records, angiographic imaging, and radiation dosimetry data (including total fluoroscopic screening time, skin dose, and dose-area product) were reviewed.

RESULTS: The mean fluoroscopic time was $13.5 \pm 13$ minutes, the mean dose-area product was $11.7 \pm 9.7 \mathrm{~Gy} . \mathrm{cm}^{2}$, and the mean total skin dose was $260.9 \pm 211.6 \mathrm{mGy}$. One hundred sixty-three of 177 procedures (92.1\%) were technically successful. In 14 (7.9\%), the initial attempt was unsuccessful (successful in 13/14 re-attempts). Screening time and radiation dose were associated with drug-delivery microcatheter location and patient age; screening time was associated with treatment cycle.

CONCLUSIONS: In selective ophthalmic artery chemosurgery, a microcatheter tip position in the proximal or ostial ophthalmic artery and patient age 2 years or younger were associated with reduced fluoroscopic screening time and radiation dose; treatment beyond the first cycle was associated with reduced fluoroscopic screening time.

ABBREVIATIONS: DAP = dose-area product; $\mathrm{OA}=$ ophthalmic artery; SOAC $=$ selective ophthalmic artery chemosurgery

$\mathbf{R}_{\mathrm{p}}^{\mathrm{e}}$ etinoblastoma is the most common pediatric ocular neoplasm, occurring in approximately 1 in 20,000 live births. In the United Kingdom, approximately 40-50 new cases are diagnosed annually. ${ }^{1}$ Retinoblastoma develops from a retinal cone precursor cell in response to bi-allelic inactivation of the $R B 1$ gene on chromosome 13. ${ }^{1,2}$ The $R B 1$ gene product is the retinoblastoma protein, a tumor suppressor. Gene mutations may be hereditary $(40 \%)$ or sporadic $(60 \%)$. Hereditary disease is more likely to present earlier with bilateral disease and be associated with other cancers.

Overall patient survival in retinoblastoma is high (exceeding 95\%) in resource-rich settings, where detection and treatment of

Received October 30, 2018; accepted after revision January 25, 2019.

From the Department of Radiology, Great Ormond Street Hospital for Children, National Health Service Foundation Trust, London, UK.

Please address correspondence to Fergus Robertson, MD, Department of Radiology, Great Ormond Street Hospital for Children NHS Foundation Trust, Great Ormond Street, London WCIN 3JH, UK; e-mail: fergusrobertson@nhs.net 7 Indicates article with supplemental on-line photo.

http://dx.doi.org/10.3174/ajnr.A6000 disease are prompt. ${ }^{3}$ Several options exist for treatment, guided by the extent of tumor spread, as determined by the International Classification of Retinoblastoma (Table 1). ${ }^{4}$ Selective ophthalmic artery chemosurgery (SOAC) has emerged as a valid treatment technique for group A-D tumors, with substantial ocular salvage rates, particularly in lower tumor grades. ${ }^{5,6}$ Potential SOAC benefits include ocular preservation and less systemic toxicity associated with standard intravenous chemotherapy regimens. Exposure to ionizing radiation during angiography and fluoroscopic positioning of the delivery microcatheter are potential detriments. Adverse effects of external beam radiation therapy treatment used historically in retinoblastoma treatment are well established. These include cataract formation, ocular dryness, facial dysmorphism, and secondary neoplasms. ${ }^{7}$ Although radiation doses used in SOAC are substantially lower than in external beam radiation therapy, this patient group is exquisitely radiosensitive (familial retinoblastoma has a predilection for second tumor formation) and strategies to minimize radiation dose are imperative (according to the As Low As Reasonably Achievable principles). ${ }^{8,9}$ This can be achieved in SOAC by judicious adjustment of fluoro- 
Table 1: The International Classification of Retinoblastoma ${ }^{4}$

\begin{tabular}{|c|c|}
\hline Group & Features \\
\hline A & Tumor $\leq 3 \mathrm{~mm}$ \\
\hline B & $\begin{array}{l}\text { Tumor }>3 \mathrm{~mm} \text { or macular location ( } \leq 3 \mathrm{~mm} \text { to foveola), } \\
\text { juxtapapillary location ( } \leq 1.5 \mathrm{~mm} \text { to disc), clear } \\
\text { subretinal fluid ( } \leq 3 \mathrm{~mm} \text { from margin) }\end{array}$ \\
\hline C & $\begin{array}{l}\text { Tumor with subretinal and/or vitreous seeds } \leq 3 \mathrm{~mm} \\
\text { from tumor }\end{array}$ \\
\hline D & $\begin{array}{l}\text { Tumor with subretinal and/or vitreous seeds }>3 \mathrm{~mm} \\
\text { from tumor }\end{array}$ \\
\hline$E$ & $\begin{array}{l}\text { Extensive retinoblastoma occupying }>50 \% \text { of globe or } \\
\text { neovascular glaucoma; opaque media from hemorrhage } \\
\text { in anterior chamber, vitreous, or subretinal space; } \\
\text { invasion of postlaminar optic nerve, choroid ( }>2 \mathrm{~mm} \text { ), } \\
\text { sclera, orbit, anterior chamber }\end{array}$ \\
\hline
\end{tabular}

scopic exposure settings, limiting screening times, and minimizing angiography. ${ }^{10}$ This study assessed SOAC radiation dose in a single center with the aim of informing further dose-reduction strategies. The study group was selected from the latter half of a 10-year institutional experience of over 320 SOAC procedures in $>100$ patients, reflecting an experienced service with established protocols.

\section{MATERIALS AND METHODS}

We conducted a retrospective review of 177 consecutive SOAC procedures, performed between January 2013 and December 2017 in 48 patients with a diagnosis of retinoblastoma. This study was registered as a Service Evaluation with the hospital Clinical Audit Department and was exempt from approval from a local research ethics committee. All patients undergoing SOAC had group $\mathrm{C}$ or D tumors, and all had relapsed after first-line systemic chemotherapy. No patients underwent SOAC as a first-line treatment. Data collection encompassed review of medical records, angiographic imaging, and radiation dosimetry data, which were obtained from our system dose reports. These included total fluoroscopic time, skin dose, and dose-area product (DAP) (currently DAP is designated Kerma area product by the International Commission on Radiologic Protection ${ }^{11}$ ). Twenty procedures in 14 patients were excluded due to incomplete dose reports. "Technical procedural failure" was defined as failure to deliver a complete planned dose of intra-arterial chemotherapy in the given treatment episode. There were no clinically apparent angiographic complications during this period.

\section{SOAC Technique}

Patients were selected for SOAC by a multidisciplinary team including oncology, ophthalmology, and neurointerventional radiology. Pediatric neurointerventional subspecialists with $>5$ years' postfellowship experience performed SOAC with the patient under general anesthesia. A 4F catheter was positioned in the ipsilateral internal carotid artery via a transfemoral approach following full intravenous heparinization $(75 \mathrm{U} / \mathrm{kg})$. A preliminary control biplane angiogram was obtained. In conventional anatomy, the ophthalmic artery was catheterized using a variety of over-thewire and flow-directed microcatheters (typically Magic microcatheter 1.2F or 1.8F; Balt, Montmorency, France) using 0.007- or 0.008-inch wires such as Hybrid 0.007 (Balt), ASAHI CHIKAI 0.008 (Asahi-Intecc, Aichi, Japan), and Mirage 0.008 (Covidien,
Irvine, California). In variant anatomy, accessory ophthalmic supply from the external carotid artery was used (typically through the anterior division of the middle meningeal artery). A single patient had bilateral SOAC in a single session (2 episodes total). This was due to synchronous bilateral disease relapse, and these 2 treatment episodes were excluded from analysis because the doses could not be separated. In all other cases with bilateral disease, a single eye was treated at each session.

Before delivering chemotherapy, we confirmed stable tip position and antegrade ophthalmic artery contrast flow with evidence of choroidal blush by superselective biplane microcatheter angiography (On-line Figure). When a stable ostial position could not be achieved in the ophthalmic artery (OA) origin, the vessel was catheterized more distally. Microcatheter tip delivery position was recorded as "origin" when located at the ostium, "proximal" when in the OA proximal to the midpoint between the ostium and the angiographic angle, and "distal" when beyond this midpoint. ${ }^{12}$ Chemotherapy was typically delivered during 30 minutes, with occasional short single-plane fluoroscopic pulses to confirm stable catheter tip position when there were stability concerns. No further angiography was performed.

\section{Fluoroscopic Protocol}

All procedures were performed on an Artis zee (Siemens, Erlangen, Germany) biplane flat panel angiography suite used exclusively for pediatric work. Digital subtraction angiography used both frontal and lateral intensifiers with automatic exposure control parameters set to maximal values of $3 \mu \mathrm{Gy}$ per frame at 4 frames per second. Fluoroscopic screening was performed with automatic adjustment of kilovolt and milliampere-second, at 7.5 or 10 pulses per second. Detector dose was set to 29 or $36 \mathrm{nGy} / \mathrm{p}$. Magnification during initial angiography was set at $32 \mathrm{~cm}$ on the frontal detector and $42 \mathrm{~cm}$ on the lateral detector and magnified to 22 or $16 \mathrm{~cm}$ on the lateral detector during superselective ophthalmic artery angiography/fluoroscopy.

The radiation dose was minimized by optimizing collimation, filtration, and reducing patient-to-detector distance and magnification when possible.

\section{Statistical Analysis}

Data are summarized by descriptive statistics. Mean and SD are reported for radiation dose parameters. By means of SPSS software, Version 25 (IBM, Armonk, New York), a 2-tailed independent-samples $t$ test was used to compare the radiation dose parameters for patient age category, treatment cycle, and successful-versus-abandoned procedures. A Kruskal-Wallis test was used to compare radiation doses among years, injected vessels, and operators. Bland-Altman statistics were used to compare the association between screening times and abandoned procedures. $P \leq .05$ was considered statistically significant for all tests.

\section{RESULTS}

Forty-eight patients underwent selective ophthalmic artery chemosurgery (male/female ratio $=22: 26)$. Thirty-three patients had bilateral retinoblastoma, and 15 had unilateral disease. In 177 procedures, $163(92.1 \%)$ were technically successful. Fourteen (7.9\%) procedures were unsuccessful, usually due to induced OA 


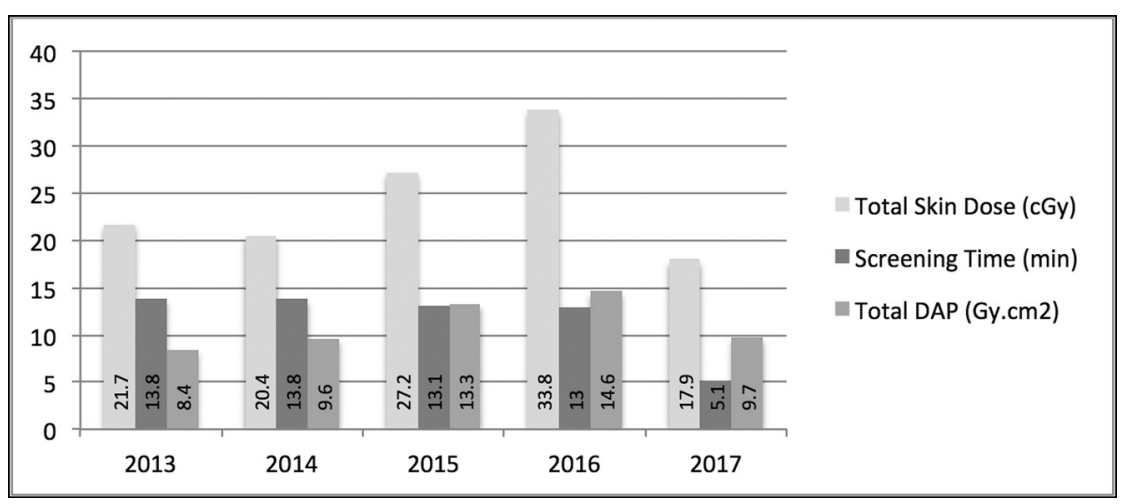

FIG 1. Mean screening times, total skin dose, and total DAP by year.

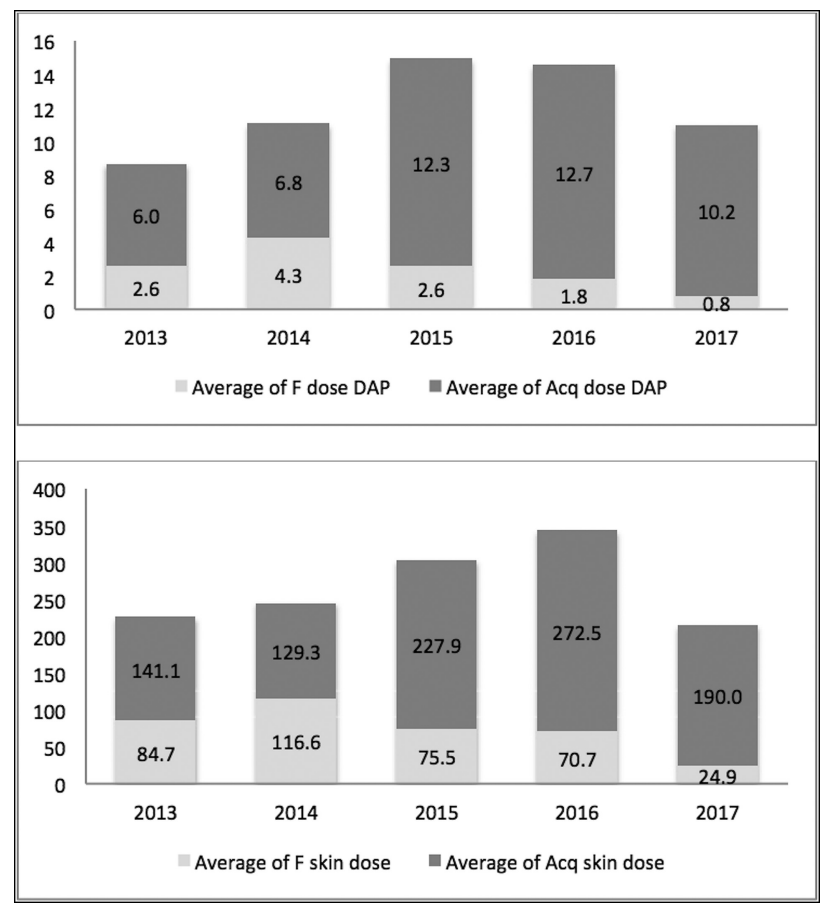

FIG 2. Angiographic acquisitions (Acq) were responsible for most of the radiation dose, and its proportion of the contribution to the overall dose gradually increased between 2014 and 2017. F indicates fluoroscopic.

ostial spasm. Repeat procedures were successful on subsequent attempts in all except 1 patient, in whom anomalous anatomy prevented stable microcatheter positioning.

The mean fluoroscopic time was $13.5 \pm 13$ minutes, (range, 1.5-67.2 minutes).

The mean dose-area product was $11.7 \pm 9.7 \mathrm{~Gy} . \mathrm{cm}^{2}$ (range, 1.7-55.4 Gy $\times \mathrm{cm}^{2}$ ).

The mean total skin dose was $260.9 \pm 211.6 \mathrm{mGy}$ (range, $43-$ $1243 \mathrm{mGy})$.

All parameters were higher in abandoned procedures: screening time $(35.7 \pm 16$ versus $11.5 \pm 10.8$ minutes $)(P<.01)$, dosearea product $\left(22 \pm 13\right.$ versus $\left.10.8 \pm 8.8 \mathrm{~Gy} . \mathrm{cm}^{2}\right)(P<.01)$, and skin dose $(543.7 \pm 255.4$ versus $236.6 \pm 189.5 \mathrm{mGy})(P<.01)$. When screening time exceeded 25 minutes, the procedure was successful in only $11 \%$ of patients, with a mean DAP of 18.5 Gy. $\mathrm{cm}^{2}$ and a skin dose of $470.7 \mathrm{mGy}$ in this group.

There was a progressive reduction in screening time during the study period, with increasing experience and latterly reflecting a move toward a more proximal/ostial OA catheter position, which was almost exclusive in 2017 (Fig 1). The total DAP and skin dose also fell in 2017. A greater proportion of the radiation dose came from angiographic acquisitions versus fluoroscopic screening (Fig 2).

In the 163 technically successful procedures, infusion was performed via the $\mathrm{OA}$ in $128(78.5 \%)$ and via the external carotid artery collateral supply to the $\mathrm{OA}$ in $35(21.5 \%)$. Of the 128 OA infusions, $67(52 \%)$ were made at the origin/ostium, $17(13 \%)$ at the proximal vessel, and $44(35 \%)$ at the distal vessel. The screening times, total DAP, and total skin doses were lower with ostial or proximal OA microcatheter tip positions compared with more distal OA or external carotid artery positions (Table 2).

Among operators, there were no significant differences in screening time $(12.3 \pm 11$ versus $10.5 \pm 10.2$ versus $14.4 \pm 15$ minutes $)$ or total DAP $(10.6 \pm 7.9$ versus $11.3 \pm 9.9$ versus $8.8 \pm$ $\left.7.1 \mathrm{~Gy} . \mathrm{cm}^{2}\right)$, though a significant difference was noted in total skin dose $(258.1 \pm 200.6$ versus $207.4 \pm 165.9$ versus $295.6 \pm$ $259.4 \mathrm{mGy}$ ).

There were significantly higher total DAP $(12.8 \pm 9.5$ versus $\left.10.8 \pm 11.3 \mathrm{~Gy} . \mathrm{cm}^{2}\right)$ and total skin doses $(281.9 \pm 218.3$ versus $194 \pm 146.6 \mathrm{mGy}$ ) in procedures performed on children older than 2 years of age. Although the screening time was also greater in this age group (12.4 \pm 10.4 versus $10.8 \pm 11.3$ minutes $)$, this difference was not significant.

Mean screening time was significantly longer in the first cycle of treatment compared with follow-up cycles $(12.7 \pm 11.5$ versus $8 \pm 7.4$ minutes). This screening time did not translate into a significant difference in radiation dose (total DAP, $10.8 \pm 8.9$ versus $11 \pm 8.7 \mathrm{~Gy} . \mathrm{cm}^{2}$; and total skin dose, $238.5 \pm 200$ versus $230.9 \pm 154.6 \mathrm{mGy}$ ) between cycles, however.

\section{DISCUSSION}

We report the radiation dose for SOAC procedures during the second 5-year period of our 10-year experience.

The mean screening time in this cohort was 13.5 minutes and mainly reflects the duration of fluoroscopic radiation exposure. This has multiple determinants, including anatomic considerations, microcatheterization strategy, fluoroscopic protocol, and operator experience. ${ }^{13}$ Lower mean screening times were reported by Cooke et $\mathrm{al}^{10}$ and Boddu et $\mathrm{al}^{14}$ at 8.5 and 10.2 minutes, respectively. However in this cohort, there was a wide range of screening times (maximal time of 67.2 minutes), and a median screening time of 7.3 minutes is more reflective of local practice.

Dose-area product/Kerma area product and patient entrance dose/skin dose are considered more accurate surrogate measures of patient radiation exposure. The DAP is a product of the radiation dose within the field and the area of tissue irradiated. This influences but is not synonymous with patient dose (which incorporates additional factors, such as patient body habitus, x-ray 
Table 2: Comparison among fluoroscopic screening time, total DAP, and total skin dose between ophthalmic artery and ECA branch injections

\begin{tabular}{lcc}
\hline & Mean ( \pm SD) & $P$ Value \\
\hline Screening time (min) & & .0001 \\
OA origin & $9.2( \pm 9.65)$ & \\
OA proximal & $11.9( \pm 7.1)$ & \\
OA distal & $14.3( \pm 11)$ & \\
ECA & $12.5( \pm 13.5)$ & .016 \\
Total DAP (Gy.cm $\left.{ }^{2}\right)$ & & \\
OA origin & $10.2( \pm 9.5)$ & \\
OA proximal & $6.9( \pm 2.9)$ & \\
OA distal & $11.3( \pm 6.6)$ & .001 \\
ECA & $13.3( \pm 11)$ & \\
Total skin dose (mGy) & & \\
OA origin & $205.7( \pm 170.7)$ & \\
OA proximal & $146.8( \pm 71.1)$ & \\
OA distal & $271.4( \pm 168.9)$ & \\
ECA & $295.7( \pm 254.7)$ & \\
\hline
\end{tabular}

Note:-ECA indicates external carotid artery.

beam quality, and radiation sensitivity of the irradiated tissue). ${ }^{15}$ The skin dose in our study measures the total skin dose (or cumulative radiation dose absorbed at the skin). Total skin dose differs from but correlates with ${ }^{16}$ peak skin dose. Peak skin dose correlates more closely with skin injury, but its calculation requires a priori analysis and is not the primary output parameter of the Siemens system. The DAP values in our series were higher than those reported by Boddu et al, ${ }^{14}$ reflecting a difference in procedural techniques. Ipsilateral internal carotid artery digital subtraction angiography was performed initially in all procedures to delineate vessel anatomy in our cohort, while others relied solely on lower dose fluoroscopic road-mapping techniques.

Figure 2 demonstrates a reduction in the component of radiation dose from fluoroscopy across the years (commensurate with reducing screening times), leading to a greater contribution to dose from angiographic acquisitions. Other dose-reducing methods such as lowering the fluoroscopic pulse rate and DSA frame rates and more active collimation and reduction of patient-intensifier distance are reflected in falling doses across time. ${ }^{17}$ Manufacturer innovations such as CAREposition (Siemens) have further helped reduce screening time. This technology allows patient repositioning in the imaging field without radiographic exposure using a moving outline box and crosshair on a last-image hold display. The procedural radiation exposure in this series remains below that described for cerebral angiography in children, but there is clearly room for further improvement. ${ }^{18}$

Extended procedures have a significant impact on radiation dose with diminishing returns. Our practice has evolved to abandon the procedure if protracted attempts at vessel catheterization are unsuccessful, particularly when faced with spasm in target vessels. In all except 1 patient, the first re-attempt was successful.

Our superselective approach (distal catheterization of the ophthalmic artery) provides a viable alternative in challenging anatomy but can be time-consuming and almost certainly contributes to increased screening times and radiation dose. Alternative strategies such temporary balloon occlusion of the ICA distal to the ophthalmic artery to redirect the microcatheter or chemotherapy into the target artery have been described by other groups. ${ }^{19}$ We have not resorted to this technique out of concern for ICA damage and distal embolism. With our approach, there have been no vessel dissections or cerebral embolic complications in $>350$ procedures. The lowest radiation doses occurred with proximal and ostial microcatheter positions, and now superselective catheterization is only used when a stable ostial position cannot be achieved.

Patients younger than 2 years of age had significantly lower radiation exposure, explained by smaller patient size, active lowering of fluoroscopic dose, and aggressive collimation.

Screening times were higher in the first cycle of treatment, compared with subsequent cycles, a finding consistent with other groups. ${ }^{14}$ Once a successful catheterization strategy is identified, this generally proves reproducible. The reduction in screening time on subsequent treatment cycle was not reflected in reduced DAP or skin dose, however, because angiographic runs contributed to the bulk of that dose.

There are limitations of a retrospective single-center study. A number of patients were excluded from the study due to incomplete dose-data recording. In our practice, SOAC was only used as salvage therapy in C and D eyes relapsed after systemic chemotherapy, whereas most published cohorts tended toward broader indications (eg, B eyes) and with SOAC as first-line treatment.

\section{CONCLUSIONS}

SOAC is established as a safe and effective treatment for retinoblastoma in selected cases in which disease is limited to the orbit. Minimizing radiation dose must be a priority in this exquisitely radiosensitive patient cohort. Our data support a strategy of proximal or ostial OA microcatheter positioning and minimizing the use of angiographic runs in favor of fluoroscopic techniques. Procedures in children younger than 2 years of age were associated with reduced screening time and radiation dose. Screening times fall in subsequent treatment cycles as a patient-specific catheterization strategy is established.

Careful procedural planning, operator experience, judicious use of dose-reducing techniques, advances in angiographic imaging technology, and the use of specific imaging equipment parameters for pediatric populations all contribute to reducing radiation dose.

Disclosures: Ayman M. Qureshi-UNRELATED: Travel/Accommodations/Meeting Expenses Unrelated to Activities Listed: MicroVention, ev3, Medtronic, Balt Extrusion, Cerenovus, Johnson \& Johnson, Penumbra, Comments: The mentioned neurovascular medical device companies have sponsored my travel and accommodation for various training courses/workshops hosted by the respective company. Adam Rennie-UNRELATED: Payment for Lectures Including Service on Speakers Bureaus: European Course in Minimally Invasive Neurological Therapy lecture.

\section{REFERENCES}

1. Yun J, Li Y, Xu CT, et al. Epidemiology and Rb1 gene of retinoblastoma. Int J Ophthalmol 2011;4:103-09 CrossRef Medline

2. Xu XL, Singh HP, Wang L, et al. Rb suppresses human cone-precursorderived retinoblastoma tumours. Nature 2014;514:385-88 CrossRef Medline

3. Broaddus E, Topham A, Singh AD. Survival with retinoblastoma in the USA: 1975-2004. Br J Ophthalmol 2009;93:24-27 CrossRef Medline

4. Shields CL, Mashayekhi A, Au AK, et al. The International Classification of Retinoblastoma predicts chemoreduction success. Ophthalmology 2006;113:2276-80 CrossRef Medline 
5. Wyse E, Handa JT, Friedman AD, et al. A review of the literature for intra-arterial chemotherapy used to treat retinoblastoma. Pediatr Radiol 2016;46:1223-33 CrossRef Medline

6. Yousef YA, Soliman SE, Astudillo PP, et al. Intra-arterial chemotherapy for retinoblastoma: a systematic review. JAMA Ophthalmol 2016 Mar 17. [Epub ahead of print] CrossRef Medline

7. Jabbour P, Chalouhi N, Tjoumakaris S, et al. Pearls and pitfalls of intraarterial chemotherapy for retinoblastoma: a review. J Neurosurg Pediatr 2012;10:175-81 CrossRef Medline

8. Strauss KJ, Kaste SC. ALARA in pediatric interventional and fluoroscopic imaging: striving to keep radiation doses as low as possible during fluoroscopy of pediatric patients-a white paper executive summary. J Am Coll Radiol 2006;3:686-88 Medline

9. Khong PL, Ringertz H, Donoghue V, et al; ICRP. ICRP Publication 121: radiological protection in paediatric diagnostic and interventional radiology. Ann ICRP 2013;42:1-63 CrossRef Medline

10. Cooke DL, Stout CE, Kim WT, et al. Radiation dose reduction in intra-arterial chemotherapy infusion for intraocular retinoblastoma. J Neurointerv Surg 2014;6:785-89 CrossRef Medline

11. 3 quantities and units for measurement and calculation in medical x-ray imaging. J ICRU 2005;5:25-34 Medline

12. Hayreh SS, Dass R. The ophthalmic artery, II: intra-orbital course. Br J Ophthalmol 1962;46:165-85 CrossRef Medline

13. Pron G, Bennett J, Common A, et al; Ontario UFE Collaborative Group. Technical results and effects of operator experience on uter- ine artery embolization for fibroids: the Ontario Uterine Fibroid Embolization Trial. J Vasc Interv Radiol 2003;14:545-54 CrossRef Medline

14. Boddu SR, Abramson DH, Marr BP, et al. Selective ophthalmic artery chemosurgery (SOAC) for retinoblastoma: fluoroscopic time and radiation dose parameters-a baseline study. JNeurointerv Surg 2017;9:1107-12 CrossRef Medline

15. Huda W. Kerma-area product in diagnostic radiology. AJR Am J Roentgenol 2014;203:W565-69 CrossRef Medline

16. Chida K, Kagaya Y, Saito H, et al. Total entrance skin dose: an effective indicator of maximum radiation dose to the skin during percutaneous coronary intervention. AJR Am J Roentgenol 2007;189: W224-27 CrossRef Medline

17. Pearl MS, Torok C, Wang J, et al. Practical techniques for reducing radiation exposure during cerebral angiography procedures. $\mathrm{J} \mathrm{Neu}$ rointerv Surg 2015;7:141-15 CrossRef Medline

18. Schneider T, Wyse E, Pearl MS. Analysis of radiation doses incurred during diagnostic cerebral angiography after the implementation of dose reduction strategies. J Neurointerv Surg 2017;9:384-88 CrossRef Medline

19. Klufas MA, Gobin YP, Marr B, et al. Intra-arterial chemotherapy as a treatment for intraocular retinoblastoma: alternatives to direct ophthalmic artery catheterization. AJNR Am J Neuroradiol 2012;33: 1608-14 CrossRef Medline 